\title{
Pedro Laín Entralgo: Medicina e Historia
}

\author{
Sergio Arturo Cañas López
}

Un cientifico que tuvo mucho renombre me dijo una vez que no estaba interesado en estudiar bistoria porque la estaba haciendo; abora está muerto $y$, por desgracia, muy poco de su obra ba resistido la prueba del tiempo.

HENRY SigERIST

Don Pedro Laín Entralgo se despojó de su envoltura corporal el 5 de junio de 2001 en Madrid, para acceder a la inmortalidad por la benemerancia de su vida y la excelencia de su obra. Nació en Urrea de Gaén, villa de la provincia de Teruel, el 15 de febrero de 1908, hijo de Pedro Laín, un médico rural ejerciente, y de Concepción Entralgo. El ámbito de la familia era pues de clase media "poco acomodada", en un pueblo muy pequeño para entonces, de algo más de mil habitantes'.

Su padre abuelo fue asimismo médico, en Huesca; con estos antecedentes no es de extrañar que hubiera un tercer médico en la línea 
de los Laín, pese a que su progenitor no quería que lo hubiese. Lo cierto es que el joven Pedro Laín Entralgo anhelaba hacer realidad el mejor de sus sueños de adolescente: ser un genio creador de ciencia ${ }^{2}$.

Tras el colegio municipal urreolano, vino la prosecución de los estudios de los estudios en distintos escenarios: Castilla, Aragón, Navarra, hasta el comienzo de la Universidad en Zaragoza. Su primera estación sería la sección de Química de la Facultad de Ciencias, que tendrá gran importancia formativa en el futuro de Laín ("cultivo teorético, al par de la química, de la nueva física"). Una beca lo llevará a Valencia a estudiar medicina en una facultad entonces de discreto nivel académico, graduándose en 1930, a los 22 años, pues llegó a la conclusión de que también por esa vía podía convertirse en un científico; fue ahí donde también descubrió su vocación antropológica esencial que marcaría el rumbo de su vida académico-profesional ${ }^{3}$.

Pronto se trasladó a Madrid en busca de lo que no encontraría en la provincia: posibilidades de formación psiquiátrica, de acrecentar sus conocimientos médicos al lado de Gregorio Marañón y de Carlos Jiménez Díaz, los grandes clínicos de la época, que eran sus paradigmas en las disciplinas hipocráticas. De aquel, sólo a través de sus libros y del coloquio no docente fue su discípulo; de este, por los avatares de la guerra civil llegó a ser un gran amigo y su alumno fuera de cátedra4. Para entonces, conoce a la sevillana Milagro Martínez, una de las primeras licenciadas en Química de España, quien fuera su esposa desde $1934^{5}$.

Su vocación antropológica ya descubierta lo lleva prontamente a hacerse psiquiatra, lo que le hace llegar a Viena, la entonces Capital Psiquiátrica de Europa, en donde realiza sus prácticas de clínica psiquiátrica y neurológica con el profesor Otto Pötzl, sucesor del famoso Ritter Julius Wagner von Jauregg, premio Nobel de Medicina en $1927^{6}$.

Era 1932, tiempos aún de apogeo del psicoanálisis de Sigmund Freud y de otros líderes heterodoxos del análisis. Laín no conoció en persona a Freud, lo que lamentó después; pero el pensamiento del maestro vienés influyó por lo menos en su aproximación a la antropología médica. Razones económicas y un concurso para médico de guardia en el Manicomio de Valencia lo trae de regreso a España y, tras posiciones breves en establecimientos psiquiátricos menores, en 
Sevilla y Valencia, se orienta definitivamente, de manera autodidacta, por la antropología y la historia de la medicina. De hecho, el mismo Laín escribe de su propia vida: "Yo era un psiquiatra sin particular afición a la clínica e intensamente atraído, en virtud de una inexorable y mal definida vocación teorética, hacia los temas de la antropología general ¿Por qué no intentar un acercamiento a la antropología médica a través de la historia de la medicina? Cerré mi tienda psiquiátrica y decidí seguir hasta el fin de mi vida el incierto camino de profesorescritor". La vocación raigal, auténtica, lo llevaría a una perspectiva antropológica por igual filosófica y médica. La inclinación por la historia remataba en una dedicación mayor a la historia de la medicina y a las bases teóricas del saber médico?.

"Soy un hombre que ha procurado cumplir con su vocación, que es dar razón intelectual suficiente de aquello que tiene ante sí y que le ocupa" afirmaba Pedro Laín Entralgo en una de las últimas entrevistas que concedió. A pesar de haber sido el referente de muchas generaciones de médicos, él confesaba humilde su impotencia ante la práctica clínica: "me siento ante el enfermo cohibido, torpe. No me muevo con la soltura del que sabe su oficio" señalaba. Sin embargo, consiguió cumplir sin asomo de duda con su vocación, dada su aportación intelectual incuestionable. Laín, con su pensamiento y obra, ha arrojado luz sobre las grandes cuestiones de la Medicina y de la vida. Si el contacto clínico con el paciente le inhibía, pensar en él le sugería ideas claves del mundo sanitario de hoy, como con respecto a la dignidad del enfermo .

Ciertamente, la vocación de Laín Entralgo no era la de médico práctico, la de curador de enfermos. Comparándolo con ese otro gigante de la inteligencia, Don Gregorio Marañón, hay facetas que los identificar y otros que los separan. Don Gregorio, antes que cualquier cosa, fue un médico practicante, un clínico sabio e infatigable; don Pedro en cambio, fue un teorizante de la Medicina, un obsesivo buceador de su historia y su destino. En lo que sí fueron pares fue en su "vocación de hombre", considerada como la más radical y básica de las vocaciones, la que conduce al conocimiento profundo y a la comprensión de ese espécimen que Linneo llamara con fortuna Homo Sapiens; pero además de su "vocación de hombre", Laín poseyó una vocación docente en grado sumo. Para él esta tiene dos supuestos: el 
saber y la voluntad de entregar a otro lo que se sabe. Como Marañón, ambos supuestos los poseyó con creces: por su sapiencia, fue profesor; por su entrega, maestro. Consideraba que el arte del verdadero maestro consiste en convertir a los alumnos en discípulos, virtud esta que don Gregorio denominada "discipulismo". Lo que Laín llamaba vocación era "aquello cuyo ejercicio otorga a la existencia de cada uno el sentido que él en su intimidad, considera más verdaderamente suyo". Siendo así, su vocación docente debe relacionarse con esa otra que él sentía como la "benéfica y ensalzadora sirena interior": la irrevocable empresa de cultivar con seriedad una Historia de la Medicina explícitamente orientada hacia la antropología médica?.

Como a otras tantas en España, la guerra civil dañó terriblemente a su familia. De tres hermanos, dos militarían durante la Guerra Civil en bandos opuestos. Pedro, nacionalista, José, republicano. La hermana mayor, Concha como la madre, era complemento de la convivencia familiar. "En su familia, como en la España de entonces, entre el espíritu religioso y conservador de la madre y el liberalismo republicano del padre, trataban de ir enseñando a los tres hijos que sí era posible la pacífica coexistencia entre españoles de diferente credo". (Albarracín) $^{10}$.

Su discípulo Diego Gracia Guillén afirma que Laín nunca fue político, pero su trayectoria incluye la militancia falangista de la que más tarde se arrepintió públicamente en su libro Descargo de conciencia. En la misma obra recuerda cómo le sorprendió el estallido de la Guerra Civil en Santander, donde había acudido como ayudante de Juan José Barcia Goyanes para impartir un curso. Incluye una anécdota en la que deja entrever un sentido del humor un tanto sarcástico. Cuando se toparon con un grupo de milicianos, Barcia le dijo a Laín que si eran coherentes con su fe debía acercarse a ellos e intentar convertirles, pero optaron por alejarse discretamente. Al relato de lo sucedido sigue un escueto comentario de Laín: "Nuestra virtud de cristianos no daba para tanto"11.

Lo cierto es que Laín se afilió a Falange y durante la contienda colaboró en Arriba España y otras publicaciones, y desde 1938 dirigió la Sección de Edición del Servicio Nacional de Propaganda, después transformada en Editora Nacional, desde donde publicó el primer libro de Xubiri Naturaleza, Historia, Dios (1942). Obviamente, su 
relación con el régimen no fue fácil. Con otros intelectuales -Luis Rosales y Antonio Marichalar entre ellos- fundó en noviembre de 1940 la revista Escorial de tono aperturista que trató de tender puentes entre los bandos que quedaron tras la Guerra Civil y al poco tiempo abandonó sus cargos políticos sufriendo la depuración a que se sometió a muchos falangistas de "procedencia dudosa". Laín Entralgo ha reflexionado al respecto: "reviso atentamente mi pasado español y encuentro en él algo de lo que debo arrepentirme: erré por ingenuidad, por desconocimiento, más de una vez por deficiencia". Laín se dedicó desde entonces a su trabajo intelectual ${ }^{12}$.

Dedicaría su vida a una producción selecta y copiosa de obras, obtuvo la titularidad de Cátedra de Historia de la Medicina en la Universidad entonces Central, hoy Complutense, de Madrid, desde 1942 y por 36 años. En 1943 fundó el Instituto Arnau de Vilanova, dedicado a la Historia de la Medicina. Fue rector de dicha universidad de 1951 a 1956, llevando a cabo el más serio intento de apertura intelectual en la universidad producido durante la época franquista. Empeñándose en restañar viejas heridas sufridas en el claustro en los largos años de represión política, devolviéndole el aire liberal y convivencial propio de una institución universitaria de elevado rango, quiso Don Pedro que volvieran, sin lograrlo, profesores proscritos, entre los principales José Ortega y Gasset y Xavier Zubiri, este último que influyera grandemente en su pensamiento filosofico y de quien se sintiera discípulo ${ }^{13}$. De hecho, Laín asistió a Zubiri en los días cruciales después de la Guerra Civil. Xubiri estaba a inicios de los 40 bajo fuerte presión de la iglesia por haber asumido el carácter de laico y casarse luego con Carmen Castro, hija del intelectual liberal Américo Castro; fue forzado a dejar la Universidad en 1942 y contó con la protección y ayuda de su amigo Laín ${ }^{14}$. Su iniciativa por recuperar a los profesores le hizo caer en desgracia con la línea oficial de Falange con la que ya discrepaba abiertamente, pero siempre hubo amigos y discípulos que estuvieron con él y que le invitaron a impartir conferencias o simplemente a compartir mesa y tertulia. Su mismo ingreso formal a la carrera docente estuvo desde inicios afectado por dificultades. Le fue otorgada la titularidad profesoral, luego de una reñida oposición, no por la calidad de los oponentes, sino por las triquiñuelas de los simpatizantes del Opus Dei, que veían en él a un dudoso seguidor de Jesucristo ${ }^{15}$. Coetáneo de Dionisio Ridruejo, Tovar, Julián 
Marías y Tierno Galván, renunció en 1956 a su cátedra en protesta por la expulsión, de sus respectivas cátedras, de López Aranguren, Tierno Galván y García Calvo.

Fue miembro de la Real Academia Nacional de Medicina, desde 1946, de la de Historia, desde 1956 y de la Real Academia Española desde 1954. De esta última fue director entre 1982 y 1987. Como académico por vocación y disciplina personal, Laín siempre tuvo una densa jornada de trabajo. Al igual que Marañón, tenía una admirable utilización del tiempo, relación que se hace más patente en la siguiente anécdota: pocos meses después de la muerte de Marañón, Don Pedro fue obsequiado por su viuda, Lola Moya, con el reloj de bolsillo, de doble tapa con monograma, que pertenecía a Don Gregorio. "El tic tac que durante años y años mecánicamente había pautado el riempo personal de Don Gregorio seguiría acompañando mis jornadas de trabajo hasta el fin de mis horas". De hecho, trabajador infatigable, Laín pese a estar jubilado concurrió al Instituto Arnau donde se reunía con sus discípulos y con los estudiantes que seguían alguna investigación. Dos de sus discípulos predilectos fueron Diego Gracia (su continuador en la cátedra de Historia de la Medicina y Antropología Médica) y Agustín Albarracín, uno de sus biógrafos más destacados $^{16}$. "Se me han muerto 53 años de mi vida. Ha muerto un amigo, un camarada, un confidente y, por encima de todo, una persona que durante más de medio siglo ha sido un amigo y mi compañero", se lamenta Albarracín al conocer que Laín había muerto, ocasión en la que también resaltó su sentido del deber. "A lo largo de una vida entera las anécdotas son muchísimas - acotaba a la redacción del Diario $M^{2}$ dico $^{17}$ - pero yo resaltaría su inquebrantable sentido del deber: la tarde en la que murió su único hermano, después del entierro, le llevé a dar una conferencia que tenía anunciada. Laín, aunque destrozado la pronunció. Sirva esto como muestra del sentido que él tenía de la responsabilidad y el deber profesional", comentó Albarracín.

Sólo así puede explicarse la prolífica producción académica de Laín Entralgo, que se reparte a lo largo de más de medio siglo, entre 53 libros, 33 obras en las que colabora como prologuista, seleccionador o editor literario y múltiples colaboraciones en publicaciones periódicas; cabe destacar de su producción relativa a la temática médica los siguientes títulos: Medicina e Historia, (Ediciones Escorial, Madrid, 1943) la que tiene como propósito demostrar que la Medicina no es 
pura ciencia natural aplicada, sino que también es ciencia social y que el acto médico es constitutivamente histórico; Estudios de Historia de la Medicina y de Antropologia Médica en donde da rienda suelta a su inclinación médico-antropológica, señalando que la contribución de la antropología médica está en partir del conocimiento de la realidad somática para alcanzar desde allí al hombre trascendente. En 1946, con el ánimo de difundir mejor las contribuciones de médicos al avance del conocimiento dio inicio a una colección llamada Clásicos de la medicina de la que fue empresario con dinero prestado. La primera entrega correspondió a Xavier Bichat, la segunda a Claudio Bernard en 1947; en 1950 publica La bistoria clínica: historia y teoria del relato patológico (Salvat Editores) que al decir del autor "ayuda al médico reflexivo a entender a profundidad lo que hace rutinariamente mediante el conocimiento del pasado, le incita a perfeccionar su conducta frente a la realidad y por tanto a moverse originalmente hacia el futuro"; de hecho, en el prólogo de la primera edición, Laín escribe “No es completa la formación intelectual de un médico mientras este no sea capaz de dar razón histórica de su saberes"18.

Por no ser rentable, tuvo que ceder la responsabilidad editorial de Clásicos de la Medicina al Consejo Superior de Investigaciones Científicas (CSIC), bajo cuyo prestigio aparecieron posteriormente los tomos dedicados a Laennec (1954), a Sydenham (1961), año en el que compendia bajo el título Grandes médicos: una visión bumana de la bistoria de la Medicina (Salvat Editores) sus trabajos relacionados con la vida y obra de médicos eminentes que hasta entonces permanecían en esfuerzos editoriales dispersos ${ }^{19}$.

Adicionalmente, en 1958, circula La curación por la palabra en la Antigüedad Clásica (Revista de Occidente), en donde desentraña la acción psicológica de la palabra y por tanto el poder curativo de la misma. Para 1964, y como prolongación de su libro Medicina e Historia, publica La relación médico-enfermo (Revista de Occidente) reeditada en 1983 (Alianza Editorial), la que constituye un análisis histórico muy serio de los vínculos entre el curador y el paciente que desde los médicos hipocráticos tuvieron a la filia, a la amistad, como el lazo más vinculante, el que da hondo sentido humanístico al quehacer médico ${ }^{20}$.

Gestado desde cuando se preparaba a concursar por la cátedra de Historia de la Medicina, aparece publicado en 1970 La medicina 
bipocrática (Revista de Occidente, reeditada por Alianza Editorial 1987), obra en la que gracias a su conocimiento del griego abordó al Corpus hippocraticum en la lengua original a través de texto publicado por Littré. Un factor inductor en la producción de esta obra fue la serie de las clases informales que en una temporada de verano recibiera de Zubiri acerca de lo que Laín Entralgo llama "el orto del pensamiento filosófico", vale decir, la constitución de physis o "naturaleza" y de or o "ente", que más tarde le servirían de fundamento a sus escritos sobre la medicina griega ${ }^{21}$.

Para concluir este rápido recuento de las obras de Laín referidas a la medicina, es obligado hacer mención a su legado más trascendente en esta área, su monumental obra Historia Universal de la medicina contenida en siete volúmenes de sin igual pulcritud editorial (Salvat, 1973), encontrándose también disponible su versión electrónica desde 1998 a cargo de Masson Multimedia, la que para muchos es considerada una obra que sólo Pedro Laín Entralgo podía dirigir. Ningún otro historiador, de cualquier época o nacionalidad, fue dueño de la capacidad y la autoridad intelectuales suyas para poder convocar $y$ obtener la colaboración de cerca de un centenar de historiadores de varios países de todos los continentes. Esta hazaña cultural resume todo lo que el saber y el quehacer de los médicos a partir del momento en que sobre la Tierra hay hombres y enfermedades ${ }^{22}$.

Sin duda, la producción de Laín acá comentada da muestra de su trabajo historiológico sobre el saber y la práctica médica; cada una de sus obras atestigua su vocación compulsiva por estudiar la estructura, leyes y condiciones de la realidad histórica de la medicina, la cual fue adoptada como su exhaustivo objeto de estudio. De hecho, fue un historiador que formó parte activa y comprometida con lo que conoció de su disciplina, de la que narró y expuso acontecimientos dignos de memoria escrutados críticamente y convencido de que la historia requiere de preguntas que buscan resolver en acercamiento y contacto con otras ciencias sociales que contribuyen a su vez a reformular nuevas preguntas y a la construcción por lo mismo, de nuevas respuestas.

Conocer a Laín es obligado punto de encuentro de quienes como él empezaron a mostrar mayor curiosidad por el pasado como una necesidad para construir sus mejores explicaciones. Particularmente, conocer a Laín y su obra ofrecerá siempre a los médicos tres cosas: 1) 
un camino hacia la integralidad de su saber, ya que por rico que intelectualmente sea el puro presente de una disciplina no agota todo lo que en relación con el tema de esta ha llegado a saberse; 2 ) una poderosa ayuda para el logro de la claridad intelectual que el ejercicio de su disciplina tan esencialmente pide y 3 ) una clara opción a favor de la originalidad científica, pues se instalará con solvencia intelectual en lo que investigue.

\section{Notas}

1. Mariátegui, J.: "Necrologla de Don Pedro Laín Entralgo (1908-2001)". Revista de Neuro-Psiquiatria. 2001. 64:279-286.

2. Sánchez Torres, F.: "Aproximación a Pedro Laln Entralgo". Instituto Colombiano de Estudios Bioéticos. http://www.encolombia.com/medicina/ academedicina (14/11/03).

3. Mariátegui, J. Opus Cit. Pág. 280.

4. Ibid.

5. Gobierno de Aragón: "Pedro Lain Entralgo". http://www.aragob.es/pre/cido/ lain.htm (13/11/03).

Europa Press. "Pedro Laín Entralgo fallece a los 93 años de edad". 5 de junio de 2001. (15/11/03)

6. Mariátegui, J. Opus Cit. Pág. 280.

7. Ibid. Pág. 281.

8. Ibid.

9. Sánches Torres, F. Opus Cit.

10. Mariátegui, J. Opus Cit.

11. Churrusca, S. Opus Cit.

12. Gobierno de Aragón. Opus Cit.

13. Mariácegui, J. Opus Cit.

14. Orringer, N.: 'Pedro Laín Entralgo (1908-2001). In Memoriam”. The Xavier Zubiri Review, Vol. 3, 2000/2001, Pp 5-6.

15. Sánchez Torres, F. Opus Cit.

16. Mariátegui, J. Opus Cit.

17. Redacción Diario Médico. "En la muerte de Pedro Laín Entralgo". 5 de junio de 2001. http://www.diariomedico.com/entorno (15/11/03)

18. Sánchez Torres, F. Opus Cit.

19. Ibid.

20. Ibid.

21. Ibid.

22. Ibid. 